Scand J Public Health. 2011 July ; 39(7 Suppl): 185-190. doi:10.1177/1403494811399170.

\title{
Register-based research on twins
}

\author{
Kaare Christensen ${ }^{1,2}$, Kirsten Ohm Kyvik ${ }^{3}$, Niels V Holm ${ }^{1,4}$, and Axel Skytthe ${ }^{1}$ \\ ${ }^{1}$ The Danish Twin Registry, Epidemiology, Institute of Public Health, University of Southern \\ Denmark, Odense, Denmark \\ 2Department of Clinical Biochemistry and Pharmacology and Department of Clinical Genetics, \\ Odense University Hospital, Odense, Denmark \\ ${ }^{3}$ Institute of Regional Health Services Research, University of Southern Denmark, Odense, \\ Denmark \\ ${ }^{4}$ Department of Oncology, Odense University Hospital, Odense, Denmark
}

\begin{abstract}
Introduction-The Danish Twin Registry (DTR) has for more than 50 years been based on surveys and clinical investigations and over the two last decades also on register linkage. Currently these two approaches are merged within Statistics Denmark.
\end{abstract}

Research topics-Here we report on three major groups of register-based research in the DTR that used the uniqueness of twinning. First, we focus on the "long-termprognosis" of being a twin compared with being a singleton and show that Danish twins have health trajectories in adulthood similar to singletons, which is a result of interest for twins and their families as well as a test of the fetal origins hypothesis that states that fetal growth restriction has long-term health consequences. Secondly, we summarise some of the most important register-based "classical twin studies", e.g. heritability studies on lifespan and exceptional longevity. Finally, we illustrate how the co-twin control method in a register setting can be used to control for the effect of rearing environment and genetic factors in studies of the association between exposures and health.

Conclusion-The spectrum of register-based twin studies is very wide and have changed in accordance with methodological and data resource developments.

\section{Keywords}

Aging; fetal origin; mortality; register; twin

\section{Introduction}

The Danish Twin Registry (DTR) was the first nationwide twin register when it was established in the early 1950s, and by 2010 it includes twins born 1870-2008 in Denmark followed on a cohort basis with large-scale linkage to other national health and social registers (Figure 1) [1,2]. The register is the basis for a wide variety of research topics and methods. Here we focus on three major groups of register-based research that use the uniqueness of twinning. The first section is on the health trajectories of twins compared to singletons. This is of interest for twins, their families, and the healthcare system (that currently produces about half the twins born through infertility treatment) as well as a test of

(C) 2011 the Nordic Societies of Public Health

Correspondence: Kaare Christensen, The Danish Twin Registry, Epidemiology, Institute of Public Health, University of Southern Denmark, J. B. Winsløws Vej 9B, DK-5000 Odense C, Denmark. kchristensen@ health.sdu.dk. 
the fetal origins hypothesis that states that fetal growth restriction has long-term health consequences. The second section summarises some register-based "classical twin studies", i.e. heritability studies that disentangle how much of the variance in a trait is due to genetic factors, shared (family) environment, and non-shared environment. The examples provided are heritability studies of lifespan and exceptional longevity. Subsequently, we illustrate how the co-twin control method in a register setting can be used to control for the effect of rearing environment and genetic factors in studies of the association between exposures and health. Finally, we point toward new designs of merging survey and clinically obtained data with register data.

\section{Research topics}

\section{Twin intrauterine growth restriction, long-term prognosis of twins, and the fetal origins hypothesis}

The DTR has devoted major effort to testing twin-singleton differences for a broad range of outcomes and phenotypes for two reasons: (1) to test whether twins are a good population model for human adult health and aging: if there were major health and aging differences between twins and singletons, the twin results may not be valid for the general population; and (2) to test the fetal origins hypothesis (the Barker-hypothesis), which states that impaired intrauterine growth "programmes" the metabolism and increases the risk for cardiovascular diseases, diabetes, and early death. Twins' birth-weight is on average about 1 $\mathrm{kg}$ less than that of singletons, and twins are therefore an extreme example of growth impairment in the third trimester.

Twins have increased mortality in the first year of life mainly due to prematurity. The Danish studies have shown no twin-singleton differences after the infancy period through register linkage with other Danish health and social registers as well as large-scale surveys. The only study showing a modest but significant difference was a study of suicide in twins, using a linkage to the Register of Causes of Death [3], which showed that twins commit suicide less often than the background population, probably due to stronger family ties. The studies have used very large samples with excellent power to detect even minimal differences. Among the key findings are: (1) Danish twins born 1870-1900 have mortality rates similar to the background population from age 6 to 90 years (Figure 2) [4] and cardiovascular mortality rates similar to the background population [5]. Danish twins have fecundity similar to singletons [6]. Contemporary Danish adolescent twins have school test results similar to singletons [7], a study based on a linkage with the DTR to Statistics Denmark data on test scores in 9th grade in the Students Register. This line of research and similar findings on mortality in the Swedish Twin Registry [8] show that twins are a good population model for health and aging research and the growth retardation experienced by twins does not generally have long-term health consequences.

\section{Example of classical twin studies: the heritability of lifespan and exceptional longevity}

Heritability is defined as the proportion of the total variance in a population that is attributable to genetic differences between individuals. Hence, a high heritability for a trait indicates that a large proportion of the individual differences in the trait is caused by genotypic or allelic differences, while a low heritability suggests that the reasons for the phenotypic differences are primarily to be sought in differences in environmental exposures or in stochastic processes of which the latter cannot be distinguished from unknown environmental exposures. The heritability concept has a number of limitations. First of all, it is time- and population-specific and sensitive to changes in the overall and the environmental variances as well as to violations of underlying assumptions. Despite these limitations, a heritability estimate is very useful because it can outline the potentials for 
identifying specific genetic or environmental factors of importance for a trait in the population from which the heritability estimate was derived [9].

The first non-censored and population-based twin study that could provide an estimate of the magnitude of genetic influences on lifespan was conducted by McGue et al. [10]. A total of 600 Danish twin pairs born 1870-1880 were included and using path analysis a heritability of 0.22 was found. Later this study was expanded by Herskind et al. [11] to include more than 2800 twin-pairs with known zygosity born 1870-1900, a study based both on church record searches and linkage to the Danish Civil Registration System for deaths after 1968. These cohorts were followed from age 15 to death. This study confirmed that approximately a quarter of the variation in lifespan in this population could be attributed to additive genetic factors while the remaining three-quarters were due to non-shared environmental factors (Figure 3). Ljungquist et al. [12] studied the 1886-1900 Swedish twin cohorts with both twins being alive in 1960 and concluded that a maximum of about one-third of the variance in longevity is attributable to genetic factors. It is interesting that animal studies have revealed similar estimates for a number of species not living in the wild $[13,14]$.

A combined analysis of the Swedish, Finnish and Danish national twin registers consisted of Nordic twin cohorts born between 1870 and 1910, a total of 20,502 individuals. The cohort was followed through 2003, so the minimum age for a twin still alive at the end of the follow-up period was 92 years of age. Using the combined data set with substantially increased statistical power, it was possible to show that prior to age 60 , there is no indication of similarity in a twin pair's age-at-death, and from age 60, a co-twin's age-at-death is significantly predictive of twin lifespan (Figure 4). These findings suggest that there are minimal genetic effects on lifespans less than 60 years, moderate genetic effects on lifespans greater than 60 years, and that the influence of genetic factors is likely to be most important at the highest ages [15]. These findings from register studies provide support for the search for genes affecting longevity in humans, especially at advanced ages.

Based on register linkage with other registers, the DTR has produced a series of twin studies of the magnitude of the genetic and environmental contribution to disease aetiology, for example linkage with: The Danish Cancer Registry for cancer [16]; The Danish National Patient Register for atrial fibrillation [17], thromboembolism [18], and Alzheimer disease [19]; the Register of Causes of Death and the Danish National Patient Register for stroke [20] and deaths due to infections [21]; the Danish Pacemaker Register and the Danish Civil Registration System for pacemaker implantation and survival in co-twins [22]; and the Danish Medical Birth Register for prolonged gestation [23].

\section{Twin studies controlling for confounding due to genetic factors and rearing environment}

The previous section dealt with the classical twin design which can disentangle the underlying causes for familial clustering of a trait. Twin studies provide completely different additional research opportunities, namely to control for confounding due to genetic factors and rearing environment. The principle is best described by monozygotic twins who share all their genes as well as rearing environment (except in the few cases where the twins were reared apart). This means that differences between monozygotic twins cannot be attributed to genetic factors or rearing environment, and therefore within-twin comparisons control for these factors in the analyses. This tool can be applied in a very broad range of risk factor studies to disentangle selection from causal effects. Here we give examples on marital status and socioeconomic condition and how they relate to mortality (to illustrate the uses of twin design in the intersection between health and social sciences).

Living alone or being unmarried are well-known risk factors for poor health in particular for men. At least two possible mechanisms have been suggested to explain the association 
between marital status and health: marriage protection and health selection. The protection hypothesis focuses on the beneficial effects of marriage through, for example, better economic security, social integration, and health behaviours. The selection hypothesis assumes that persons with certain traits or behaviour, influenced by their genotypes or early environments, are selected into marriage while some persons, such as people with health problems, are at a higher risk of never marrying, and if married, of divorcing. We can make the following predictions in this co-twin control design: if the association of adult marital status and mortality reflects selection effects only, then we do not expect health differences in monozygotic twin pairs discordant on adult marital status, because these twins are concordant on early rearing environmental and genetic factors. Alternatively, health outcome differences in dizygotic but not in monozygotic pairs discordant for adult marital status would suggest that genetic factors underlie selection effects, because dizygotic twins share the same rearing environment, but share only half their genetic variants. Finally, a direct (causal) beneficial effect of marriage would be implicated by finding that both monozygotic and dizygotic twins discordant for marital status are also discordant on health and behaviour outcomes. We are currently conducting such studies in Denmark to investigate whether differences in marital status (obtained through the Danish Demographic Database) influence the health (obtained through the Danish National Patient Register and the Danish National Prescription Registry) of twins who share genetic constitution and rearing environment and how that differs between males and females [24].

A few studies using this co-twin control design have investigated the basis for the association between socioeconomic status and health outcomes. A smaller Danish study [25] showed that the relationship between social class and health is due mainly to selection effects rather than being a causal effect of social class exposures on health and behaviour. A similar US study found the opposite result, which was that the relationship between social class and health is due mainly to direct causal effects [26]. It is unclear whether this contradictory result is due to the different settings (Denmark has a more egalitarian social system than the USA) or a chance finding due to small sample size. The Danish study was recently replicated as a large-scale data-based register study of education and survival using the above mentioned registers at Statistics Denmark, and again the results were most compatible with an effect of early family environment in explaining the Danish educational inequalities in mortality [27]. In the examples given above, the outcome was health related and the exposure was a demographic characteristic (marital status/socioeconomic status/ education), but the design is generally applicable.

\section{Conclusion}

Twin studies provide unique research opportunities through various designs. The classical twin studies use the difference in similarity between monozygotic and dizygotic twins to disentangle genetic and environmental contribution to complex traits while the twin-co-twin control design matches for rearing environment and genetic factors. Concerns have been raised that the growth restriction experienced by twins in fetal life would affect their health in later life. However, twins in Denmark have mortality and health trajectories in adulthood similar to singletons. Danish twin research has over last 50 years been based on surveys and clinical investigations and over the last decades also on register research. Currently, these two approaches are merged within Statistics Denmark, which will provide additional leverage and research opportunities in the future.

\section{Acknowledgments}

We wish to thank the following for their considerable financial contribution to the foundation and the continued support of the Danish Twin Registry: the Danish Research Council, University of Southern Denmark, the Danish 
National Research Foundation, the National Program for Research Infrastructure 2007 from the Danish Agency for Science Technology and Innovation, Helsefonden, the Danish Diabetic Association, the Danish Heart Foundation, the Novo Nordisk Foundation, Unilever, the Velux Foundation, the United States National Institute on Aging (P01AG08761), and the GenomEUtwin under the EU's 5th Framework Program.

Funding

This research received no specific grant from any funding agency in the public, commercial, or not-for-profit sectors.

\section{References}

1. Skytthe A, Kyvik KO, Holm NV, Christensen K. The Danish Twin Registry. Scand J Public Health. 2011; 39(Suppl 7):75-78. [PubMed: 21775358]

2. Skytthe A, Kyvik K, Holm NV, Vaupel JW, Christensen K. The Danish Twin Registry: 127 birth cohorts of twins. Twin Res. 2002; 5(5):352-357. [PubMed: 12537858]

3. Tomassini C, Juel K, Holm NV, Skytthe A, Christensen K. Risk of suicide in twins: 51 year follow up study. BMJ. 2003; 327(7411):373-374. [PubMed: 12919989]

4. Christensen K, Vaupel JW, Holm NV, Yashin AI. Mortality among twins after age 6: fetal origins hypothesis versus twin method. BMJ. 1995; 310(6977):432-436. [PubMed: 7873948]

5. Christensen K, Wienke A, Skytthe A, Holm NV, Vaupel JW, Yashin AI. Cardiovascular mortality in twins and the fetal origins hypothesis. Twin Res. 2001; 4(5):344-349. [PubMed: 11869487]

6. Christensen K, Basso O, Kyvik KO, Juul S, Boldsen J, Vaupel JW, et al. Fecundability of female twins. Epidemiology. 1998; 9(2):189-192. [PubMed: 9504289]

7. Christensen K, Petersen I, Skytthe A, Herskind AM, McGue M, Bingley P. Comparison of academic performance of twins and singletons in adolescence: follow-up study. BMJ. 2006; 333(7578):1095. [PubMed: 17012267]

8. Vågerö D, Leon D. Ischaemic heart disease and low birth weight: a test of the fetal-origins hypothesis from the Swedish Twin Registry. Lancet. 1994; 343(8892):260-263. [PubMed: 7905096]

9. Plomin, R.; DeFries, JC.; McClearn, GE.; McGuffin, P. Behavioral genetics. 5th edn. New York: Worth Publisher; 2008.

10. McGue M, Vaupel JW, Holm N, Harvald B. Longevity is moderately heritable in a sample of Danish twins born 1870-1880. J Gerontol. 1993; 48(6):B237-B244. [PubMed: 8227991]

11. Herskind AM, McGue M, Holm NV, Sørensen TI, Harvald B, Vaupel JW. The heritability of human longevity: a population-based study of 2872 Danish twin pairs born 1870-1900. Hum Genet. 1996; 97(3):319-323. [PubMed: 8786073]

12. Ljungquist B, Berg S, Lanke J, McClearn GE, Pedersen NL. The effect of genetic factors for longevity: a comparison of identical and fraternal twins in the Swedish Twin Registry. J Gerontol A Biol Sci Med Sci. 1998; 53(6):M441-M446. [PubMed: 9823748]

13. Curtsinger JW, Fukui HH, Khazaeli AA, Kirscher A, Pletcher SD, Promislow DE, Tatar M. Genetic variation and aging. Annu Rev Genet. 1995; 29:553-575. [PubMed: 8825486]

14. Finch CE, Tanzi RE. Genetics of aging. Science. 1997; 278(5337):407-411. [PubMed: 9334291]

15. vB Hjelmborg J, Iachine I, Skytthe A, Vaupel JW, McGue M, Koskenvuo M, et al. Genetic influence on human lifespan and longevity. Hum Genet. 2006; 119(3):312-321. [PubMed: 16463022]

16. Lichtenstein P, Holm NV, Verkasalo PK, Iliadou A, Kaprio J, Koskenvuo M, et al. Environmental and heritable factors in the causation of cancer - analyses of cohorts of twins from Sweden, Denmark, and Finland. N Engl J Med. 2000; 343(2):78-85. [PubMed: 10891514]

17. Christophersen IE, Ravn LS, Jørgensen EB, Skytthe A, Hauns $\emptyset$ S, Svendsen JH, et al. Familial aggregation of atrial fibrillation - a study in Danish twins. Circ Arrhythm Electrophysiol. 2009; 2(4):378-383. [PubMed: 19808493]

18. Larsen TB, Sørensen HT, Skytthe A, Johnsen SP, Vaupel JW, Christensen K. Major genetic susceptibility for venous thromboembolism in men: a study of Danish twins. Epidemiology. 2003; 14(3):328-332. [PubMed: 12859034] 
19. Christensen K, Holm NV, Vaupel JW. Alzheimer's disease in twins. [Letter with original data]. Lancet. 1996; 347(9006):976. [PubMed: 8598793]

20. Bak S, Gaist D, Sindrup SH, Skytthe A, Christensen K. Genetic liability in stroke. A long-term follow-up study of Danish twins. Stroke. 2002; 33(3):769-774. [PubMed: 11872902]

21. Obel N, Christensen K, Petersen I, Sørensen TI, Skytthe A. Genetic and environmental influences on risk of death due to infections assessed in Danish twins, 1943-2001. Am J Epidemiol. 2010; 171(9):1007-1013. [PubMed: 20375195]

22. Tveskov C, Skytthe A, Arnsbo P, Vaupel JW, Moller M, Christensen K. Twins with implanted pacemakers: is there an increased mortality risk for the co-twin? A follow-up study based on the Danish Twin Registry and the Danish Pacemaker Register. Europace. 2005; 7(6):598-603. [PubMed: 16216763]

23. Laursen M, Bille C, Olesen AW, Hjelmborg J, Skytthe A, Christensen K. Genetic influence on prolonged gestation: a population-based Danish twin study. Am J Obstet Gynecol. 2004; 190(2): 489-494. [PubMed: 14981395]

24. Oksuzyan A, Juel K, Vaupel JW, Christensen K. Men: good health and high mortality. Sex differences in health and ageing. Aging Clin Exp Res. 2008; 20(2):91-102. [PubMed: 18431075]

25. Osler M, McGue M, Christensen K. Socioeconomic position and twins' health: a life-course analysis of 1266 pairs of middle-aged Danish twins. Int J Epidemiol. 2007; 36(1):77-83. [PubMed: 17251245]

26. Krieger N, Chen JT, Couli BA, Selby JV. Lifetime socioeconomic position and twins' health: and analysis of 308 pairs of United States women twins. PloS Med. 2005; 2(7):e162. [PubMed: 16033303]

27. Madsen M, Nybo Andersen A-M, Christensen K, Andersen PK, Osler M. Does educational status impact adult mortality in Denmark? A twin approach. Am J Epidemiol. 2010; 172(2):225-234. [PubMed: 20530466] 


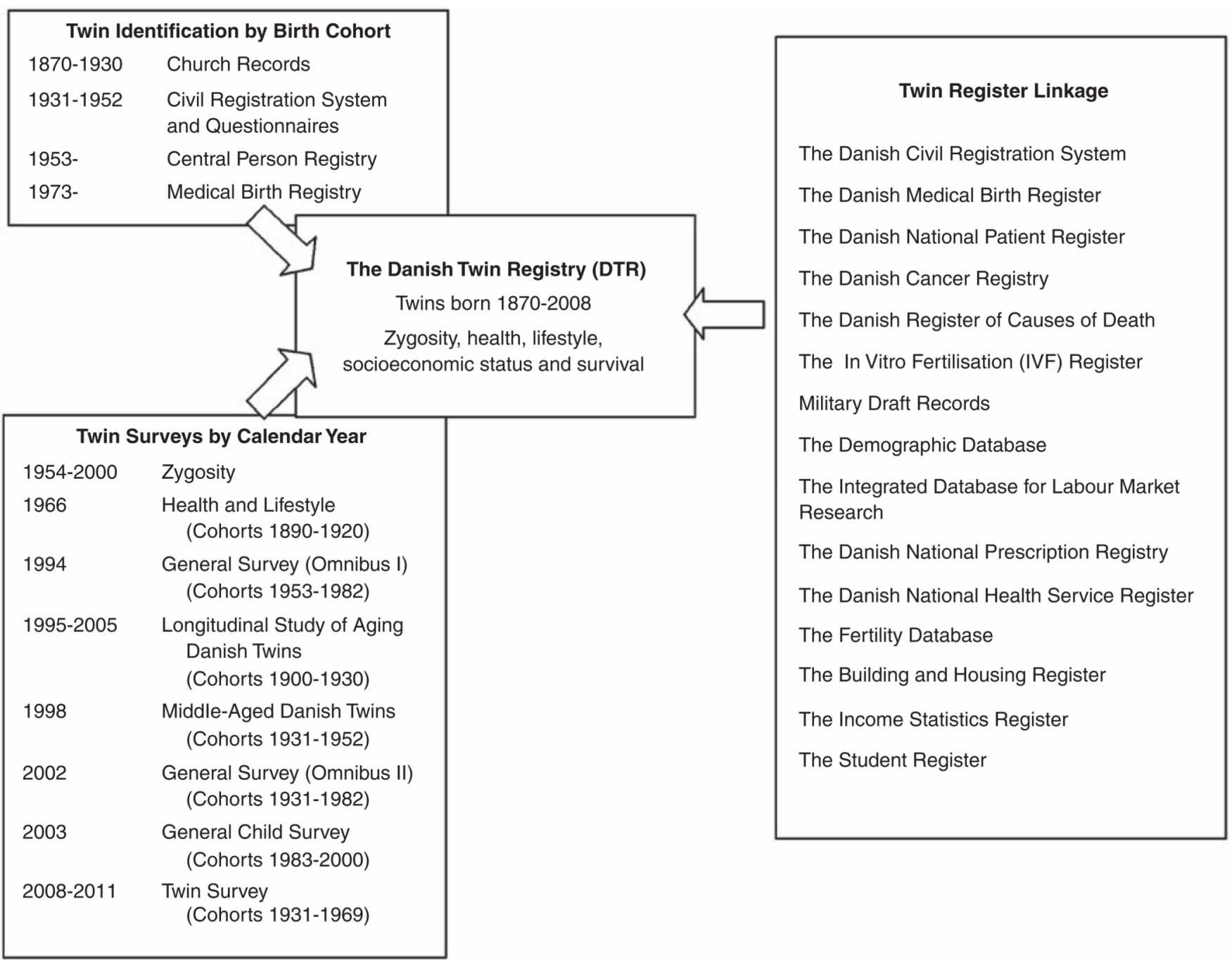

Figure 1.

Data sources used in the establishment of the Danish Twin Registry. 


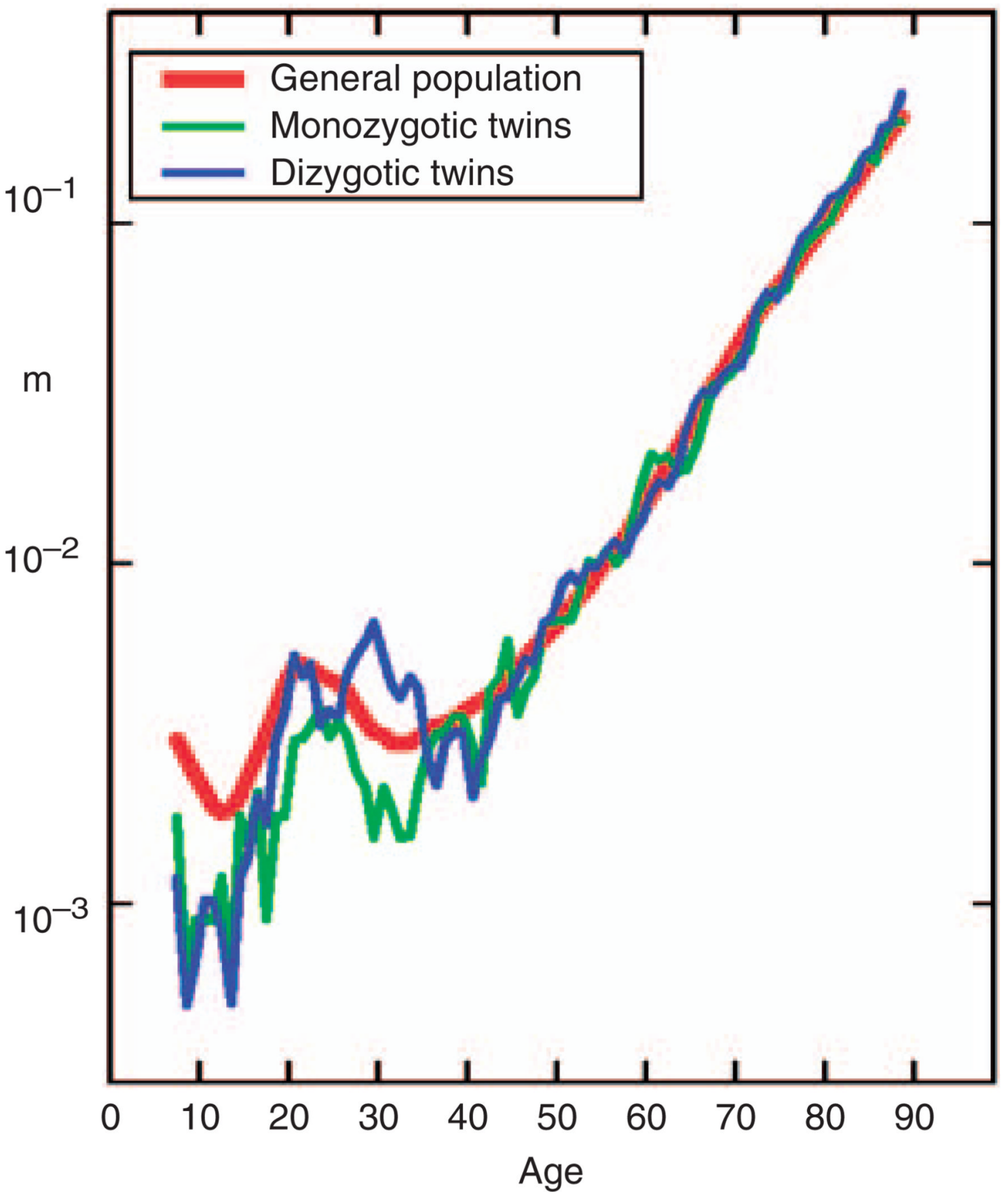

Figure 2.

Mortality rates from age 6 to age 90 on a cohort basis for twins and the Danish general population born 1870-1900. There is no indication of increased mortality for twins [4]. 

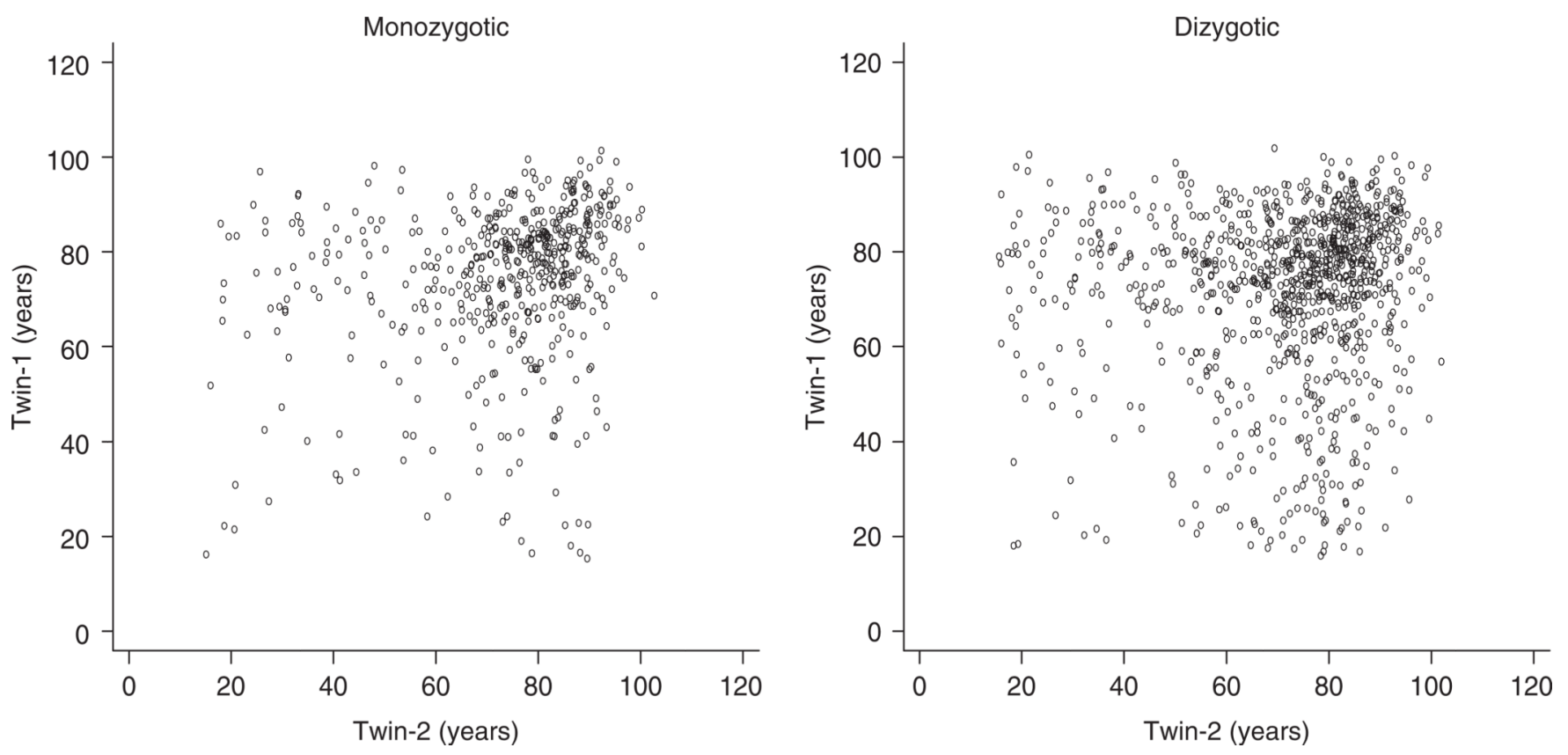

Figure 3.

Similarity in lifespan for monozygotic and dizygotic Danish twins of the same sex from cohorts born 1870-1900 and who survived to at least age 15. Each dot in the graphs represents a twin pair. The pattern suggests that approximately one quarter of the variation in lifespan can be attributed to genetic factors [11]. 


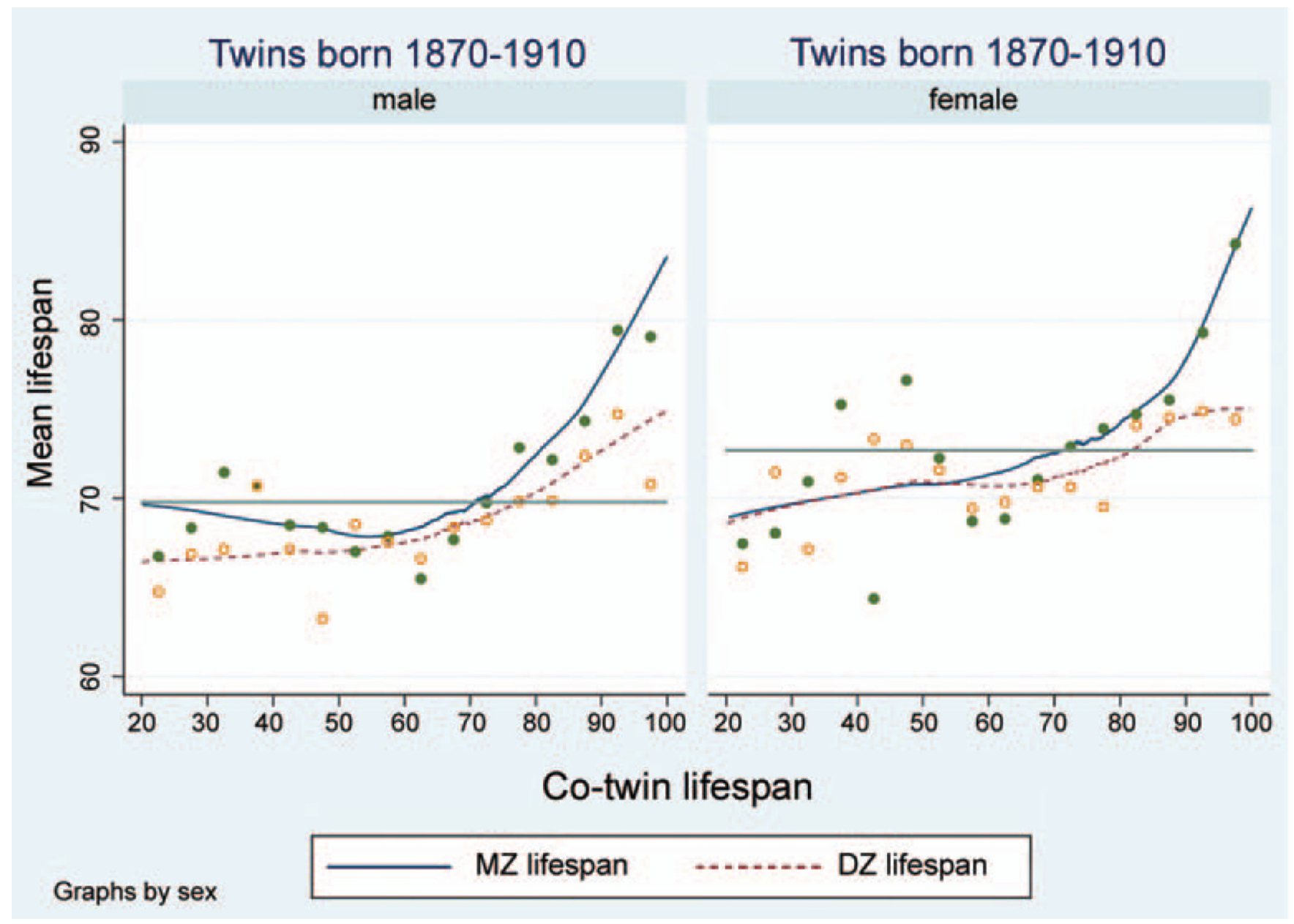

Figure 4.

Mean lifespan of twin given lifespan of co-twin of Danish twin cohort 1870-1910. Dots denote mean lifespan of twin given 5 year lifespan interval of co-twin (MZ twins by solid circles, DZ twins by hollow circles). The curves arise from lowess smoothing (bandwidth 0.8). Horizontal lines are mean lifespan for the whole sample (males and females respectively). The patterns suggest that there are minimal genetic effects on lifespans less than 60 years, moderate genetic effects on lifespans greater than 60 years, and that the influence of genetic factors is likely to be most important at the highest ages [15]. 